Withbroe, G. L. $\quad$ 1971, Solar Phys. 18, 458.

Withbroe, G. L., Dupree, A. K., Goldberg, L., Huber, M. C. E., Noyes, R. W., Parkinson, W. H., and Reeves, E. M. 1971, Solar Phys. 21, 272.

Wöhl, H. 1972, Solar Phys. 24, 342.

Wöhl, H., Wittman, A., and Schröter, E. H. $\quad$ 1970, Solar Phys. 13, 104.

Wood, A. T., Jr., Noyes, R. W., Dupree, A. K., Huber, M. C. E., Parkinson, W. H., Reeves, E. M., and Withbroe, G. L. $\quad$ 1972, Solar Phys. 24, 169.

Wood, A. T., and Noyes, R. W. 1972, Solar Phys. 24, 180.

Yakovkin, N. A., and Zel'dina, M. Yu. 1971, Solar Phys. 19, 414.

Yeh, T., and Axford, W. I. 1970, J. Plasma Phys. 4, 207.

Yoshimura, H. 1971, Solar Phys. 18, 417.

Yoshimura, H., Tanaka, K., Shimizu, M., and Hiei, E. $\quad$ 1971, Publ. Astron. Soc. Japan 23, 443.

Yun, H. S. 1970, Astrophys. J. 162, 975.

Yun, H. S. 1971a, Solar Phys. 16, 379.

Yun, H. S. 1971b, Solar Phys, 16, 398.

Zhugzhda, Y. D. 1971, Cosmic Electrodyn. 2, 253.

Zirin, H. $\quad 1971$, IAU Symp. 43, p. 237.

Zirin, H. 1972, Solar Phys. 22, 34.

Zirin, H., Pruss, G., and Vorpahl, J. 1971, Solar Phys. 19, 463.

Zirker, J. B. 1971, in Physics of the Solar Corona, Macris, ed., p. 140 (Reidel, Dordrecht).

Zvereva, A. M., and Severny, A. B. $\quad$ 1970, Izv. Krymsk. Astrofiz. Obs. 41-42, 97.

Zwaan, C., and Buurman, J. $\quad$ 1971, IAU Symp. 43, p. 220.

SOLAR RADIO ASTRONOMY*

D. J. McLean

\title{
General
}

The English translation of Zheleznyakov's comprehensive book Radio Emission of the Sun and Planets appeared in 1970. A new review of 'the radio emission from travelling disturbances in the corona - type III, type II and moving type IV bursts...' has recently been published (Wild and Smerd, 1972). A review of the earlier data from the Culgoora radioheliograph will be found in Wild (1970).

Publications which have not been included individually in the references but which are of general interest can be found in the proceedings of the conferences of the Committee of European Solar Radio Astronomers (CESRA) (editors Fokker, Abrami) and Physics of the Solar Corona (editor Macris, 1971). The latter includes a review of space radio-astronomy observations by Papagiannis (1971).

\section{Spectrograph observations}

Spectrograph observations up to kilometre wavelengths are discussed under space radio astronomy.

Radio spectrograph observations continue to bear fruit. At decimetre wavelengths using a highly sensitive, differentiating spectrograph Slottje (1972) has observed a great variety of micro structures during a type IV event, and Rosenberg (1972) has attempted to explain some of them. The occurrence of striking examples of a previously known phenomenon - regular pulsations in type IV events - has stimulated theoretical interest (Rosenberg 1970; McLean et al., 1971; Abrami 1970, 1972) and the publication of more observational data (Gotwols, 1972; Kai, 1973; Caroubalos et al. 1973).

At metre wavelenghts Markeev and Chernov (1970) have also seen unusual bursts and Tarnstrom and Phillips (1972) have made a high-resolution study of what they call spike bursts.

Boischot et al. (1971) have studied the discontinuity in storm activity at about the boundary between

* This note was received too late to be included in the final Commission Report. 
metre and decametre wavelengths and de la Noë and Boischot (1972) have identified a type of burst, previously described by Ellis and McCulloch (1966), as a precursor of normal type III bursts. Lacombe and Møller Pedersen (1971) have observed unusual evidence of interaction between the electrons producing type III bursts and a slow shock-wave phenomenon.

\section{Type I storms}

As with recent work in a number of other areas of solar radio astronomy, much of the work on type I storms (including continuum) has sought to give some information about coronal magnetic fields, although the interpretations are generally tentative as yet (Lantos-Jarry, 1970; Kai, 1970; Daigne et al., 1971; Sakurai and Stone, 1971; Sakurai, 1971a, b; McLean and Sheridan, 1972; Stewart and Labrum, 1972). The relation between type I storms and low-frequency type III storms has been emphasized in a number of these papers. Gordon (1970) has proposed the basis of a theory of this relationship.

\section{Type II bursts}

A number of radioheliograph observations of type II bursts have been interpreted (Dulk, 1971a, 1971; Dulk and Smerd, 1971) as indicating 'backward emission' of the harmonic component, although another case possibly favours forward emission (Riddle, 1970).

Perhaps the most interesting single observation was of a type II burst produced by a behind-thelimb flare which outlined the west limb from north to south pole. The interest in this event comes from the implications concerning the path of the shock (Smerd, 1970; Dulk et al., 1971). Another observation, which gives results of similar significance, has been analysed by Newkirk (1971).

A new theoretical study of shock waves and type II emission has recently appeared (Smith, 1971, 1972a, b). However, these theoretical models are for perpendicular shocks, and the observations of Smerd and Dulk et al. suggest that we should also consider parallel shocks (i.e. magnetic field parallel to direction of shock motion). The propagation of shock waves produced by type II bursts has been studied by Garczynska (1971) and Pintér (1972).

\section{Type III bursts (see also under Space Radio Astronomy)}

One-dimensional radioheliograph observations at $169 \mathrm{MHz}$ (Bougeret et al., 1970) show a curious drift of source position with time, sometimes also a jump, which may be associated with harmonic structure.

At $80 \mathrm{MHz}$ Stewart $(1972,1973)$ has studied the relative positions of positively identified fundamental and harmonic pairs in relation to recent work on scattering (see below).

Other new observational results are the correlation of some type III bursts with short-lived absorption features observed in the wings of $\mathbf{H} \alpha$ (Martres et al., 1972) and the correlation with soft X-ray bursts investigated by Teske et al. (1971).

The observation of a component of linear polarization in type III bursts is something of a mystery. Despite reports of linear polarization by Chin et al. (1971) and others, Grognard and McLean (1973) could find no evidence of Faraday rotation or linear polarization. Linear polarization is further discussed by Fokker (1971).

Considerable theoretical effort has gone into the explanation of type III bursts (Smith, 1970a, b, 1972c; Smith and Fung, 1971; Smith and Sturrock 1971; Melrose, 1970a, b). In contrast to these authors, Zheleznyakov and Zaitsev (1970a, b) and Zaitsev et al. (1972) have taken account of the finite extent of the stream, and find the problem of stabilization of the exciter stream much easier (see also Baldwin, 1964). The validity of this approach is supported by observations of radiation from the front of a stream of electrons injected artificially into the Earth's ionosphere (Cartwright and Kellogg, 1971a, b; Wild and Smerd, 1972). Melrose and Sy (1972) have made a detailed study of the effects of a magnetic field within the source on the polarization of type III radiation and they find that the observed degree of circular polarization implies startlingly small magnetic 
fields in the sources. Fomichev and Chertok (1970) have studied other aspects of the interpretation of polarization in type III bursts.

Continued studies of the effects of scattering of radiation by inhomogeneities in the corona are leading to a better understanding of source sizes, disk distributions, relative positions of fundamental and harmonic, and polarization of type III bursts (Steinberg et al., 1971; Aubier et al., 1971; Steinberg, 1972; Caroubalos et al., 1972; Riddle, 1972a, b, 1973; Stewart, 1973; Fokker, 1971). Space observations of type III bursts are also providing new tests of type III theories (Evans et al., 1971; Smith, 1972d).

Studying U-bursts, Labrum and Stewart (1970) have observed separate positions at $80 \mathrm{MHz}$ for the up-and-down legs. They also interpret 29 spectra in terms of a path in the corona. Fokker (1970) has made a similar analysis of five individual U-bursts spectra. Daene (1971) has studied the magnetic configurations likely to be responsible. These bursts have also been observed turning over at frequencies as low as $0.7 \mathrm{MHz}$ (Stone and Fainberg, 1971).

\section{Type IV bursts}

Structure in the spectra of type IV bursts is discussed in another section.

The interest in moving-type-IV emission has continued (Wild, 1970). Smerd and Dulk (1971) have collected and studied a group of 12 bursts which they are able to divide into three different classes, and these classes appear to require explanations by different types of models. Lacombe and Mangeney (1969) have developed the theory of a shock front model. Dulk (1970b) and Schmahl $(1972,1973)$ have sought to explain the evolution of radiation and its polarization in a magnetized-blob model. Hansen et al. (1971) report the disappearance of a short-lived coronal condensation observed in white light simultaneously with a moving-type-IV source.

The complex of events generally grouped under the term 'type IV' has been further analysed by Akinyan et al. (1971) and Böhme (1972).

Kundu et al. (1970) observe frequency dispersion in the position of type IV bursts in the range 20 to $60 \mathrm{MHz}$, and so conclude that there is generally no 'synchrotron part' of these bursts at decametric wavelengths.

\section{Space Radio Astronomy}

From space observations considerable data has been collected on the occurrence of type III bursts below $5 \mathrm{MHz}$ and their association with solar flares (Haddock and Graedel, 1970; Graedel, 1970).

From an analysis of a storm of type III bursts observed in the range 2.8 to $0.54 \mathrm{MHz}$ Fainberg and Stone (1970a, b, 1971) were able to determine the velocity of the exciter (electron stream), the variation of electron density with height between 14 and $36 R_{\odot}$, and even the solar wind velocity. Observations of type III bursts down to frequencies as low as $25 \mathrm{KHz}$ (Dunckel et al., 1972) show remarkable continuity with observations at higher frequencies. Space observations of electrons with energy $<40 \mathrm{keV}$ suitably delayed after type III bursts lend support to the identification of type III bursts with electron streams (Alvarez et al., 1972). However, this result is not supported by Graedel and Lanzeroti (1971).

At metre wavelengths, simultaneous observations from a space probe and ground-based instruments promise to give new information about burst directivity (Steinberg and Caroubalos, 1970).

Measurements of the Faraday rotation of radiation from a space probe on the other side of the Sun have been used by Scatten (1970) to study the coronal magnetic fields.

\section{Slowly-varying component}

From observations at $169 \mathrm{MHz}$ (Axisa et al., 1971) sources of the slowly-varying component are linked with filaments and the corresponding coronal structures (helmet and active streamers). They have also been related to interplanetary sectors (Matres et al., 1970). 


\section{Microwaves}

Much of the current interest in microwave bursts comes from their similarity to X-ray bursts (Harries, 1970; Takakura et al., 1971; Hudson and Ohki, 1972; Takakura, 1971; Gel'freikh et al., 1970) or EUV bursts (Castelli and Richards, 1971). Croom (1971a, b) has studied the relation between microwave bursts and solar protons.

By observing a single active region Richards and Straka (1971) have found variations of the degree of polarization just prior to a burst, while Kaufmann et al. (1970) and Scalise et al. (1972) have made studies of the variation of polarization during microwave bursts. Some interesting individual results are coming from the Japanese rapid-scan interferometer operating at $8 \mathrm{~cm}$ (Tanaka et al., 1970; Tanaka and Énomé, 1970, 1971; Énomé and Tanaka, 1971; Énomé, 1972). It is planned to expand this instrument to provide for twodimensional operation (Ishiguro et al., 1972). This instrument will rely on the phase calibration methods developed by Arisawa (1971) and Ishiguro (1971).

\section{Millimetre-wave observations}

A number of observers have produced maps of the Sun at different millimetre wavelengths (Kundu, 1970, 1971, 1972; Kundu and McCullough, 1972; Mayfield et al., 1970; Buhl and Tlamicha, 1970; Cogdell, 1972; Efanov et al., 1972; Shimabukuro, 1970a, 1971; Beckman and Clark, 1971; Feix, 1972). Shimabukuro $(1970 \mathrm{~b}, 1972)$ has used repeated scanning to study $3 \mathrm{~mm}$ bursts and he finds interesting results concerning their flux, spectrum, brightness temperature and correlation with soft X-ray bursts. Others have used solar eclipses to improve the resolution of their observations (Hagen et al., 1971; Simon, 1971; Flett et al., 1971; Simon and Wickström, 1971). A recent search for recombination lines in solar emission has been unsuccessful (Berger and Simon, 1972).

A review of millimetre radio astronomy, including a section on solar observations, has recently been published (Kislyakov, 1970).

\section{Occultations}

Observations of occultations of Taurus A by the solar corona continue to give information about the effect of solar activity on the outer corona (Krygier, 1970; Gorgolewski, 1972; Baselyan et al., 1970, 1971). Two new innovations are the measurement of the Faraday rotation (Sofue et al., 1972) and measurement of the added dispersion in pulses from the pulsar in Taurus A (Counselman and Rankin, 1972, 1973). The first gives some indication of the magnetic structure of the corona, the latter gives a direct measure of electron densities.

\section{BIBLIOGRAPHY}

Abrami, A. $\quad$ 1970, Solar Phys. 11, 104.

Abrami, A. $\quad$ 1972, Nature Phys. Sci. 238, 25.

Abrami, A. (ed.) 1972, Proceedings of the Second Meeting of the Committee of European Solar Radio Astronomers, Trieste.

Akinyan, S. T., Mogilevsky, E. I., Böhme, A., and Krüger, A. $\quad$ 1971, Solar Phys. 20, 112.

Alvarez, H., Haddock, F., and Lin, R. P. $\quad$ 1972, Solar Phys. 26, 468.

Arisawa, M. 1971, Proc. Res. Inst. Atmos. Nagoya Univ. 18, 89.

Axisa, F., Avignon, T., Martres, M. J., Pick, M., and Simon, P. $\quad$ 1971, Solar Phys. 19, 110.

Aubier, M., Leblanc, Y., and Boischot, A. 1971, Astron. Astrophys. 12, 435.

Baldwin, D. E. $\quad$ 1974, Phys. Letters 12, 202.

Baselyan, L. L., Braude, S. Ya., and Men', A. V. $\quad$ 1970, Astron. Zh. 47, $188 \quad$ 1970, Soviet Astron.-AJ 14,153 .

Baselyan, L. L. and Sinitsin, V. G. 1971, Solar Phys. 17, 129.

Beckman, J. E. and Clark, C. D. 1971, Solar Phys. 16, 87.

Berger, P. S. and Simon, M. 1972, Astrophys. J. 171, 191.

Böhme, A. 1972, Solar Phys. 24, 454. 
Boischot, A., de la Noë, J., du Chauffaut, M., and Rosolen, C. 1971, CR Acad. Sci. 272, 166.

Bougeret, J.-L., Caroubalos, C., Mercier, C., and Pick, M. 1970, Astron. Astrophys. 6, 406.

Buhl, D. and Tlamicha, A. 1970, Astron. Astrophys. 5, 102.

Caroubalos, C., Aubier, M., Leblanc, Y., and Steinberg, J.-L. $\quad$ 1972, Astron. Astrophys. 16, 374.

Caroubalos, C., Pick, M., Rosenberg, H., and Slottje, C. 1973, (in preparation).

Cartwright, D. G. and Kellogg, P. J. 1971a, Nature, Phys. Sci. 231, 11.

Cartwright, D. G. and Kellogg, P. J. 1971b, Proc. ESRO Conf., "Wave-Particle Interactions in the Magnetosphere", ESRO, Neuilly-sur-Seine (France), p. 75.

Castelli, J. P. and Richards, D. W. 1971, J. Geophys. Res. 76, 8409.

Chin, Y. C., Lusignan, B. B., and Fung, P. C. W. 1971, Solar Phys. 16, 135.

Cogdell, J. R. 1972, Solar Phys. 22, 147.

Counselman, III, C. C. and Rankin, J. M. 1972, Astrophys. J. 175, 843.

Counselman, III, C. C. and Rankin, J. M. 1973, Astrophys. J. (in press).

Croom, D. L. 1971a, Solar Phys. 19, 152.

Croom, D. L. 1971b, Solar Phys. 19, 171.

de la Noë, J. and Boischot, A. 1972, Astron. Astrophys. 20, 55.

Daene, A. $\quad$ 1971, Heinrich-Hertz-Institut Solar-Terr. Phys., Suppl. Ser., Solar Data, 2, 241.

Daigne, G., Lantos-Jarry, M. F., and Pick, M. 1971, In "Solar Magnetic Fields" (ed. R. Howard), IAU Symp. 43, D. Reidel, Dordrecht, Holland, p. 609.

Dulk, G. A. 1970a, Proc. Astron. Soc. Australia 1, 308.

Dulk, G. A. 1970b, Proc. Astron. Soc. Australia 1, 372.

Dulk, G. A. 1971, Australian J. Phys. 24, 177.

Dulk, G. A., Altschuler, M., and Smerd, S. F. 1971 , Astrophys. Letters 8, 235.

Dulk, G. A. and Smerd, S. F. $\quad$ 1971, Australian J. Phys. 24, 185.

Dunckel, N., Helliwell, R. A., and Vesecky, J. 1972, Solar Phys. 25, 197.

Efanov, V. A., Kislyakov, A. G., and Moiseev, I. G. $\quad$ 1972, Solar Phys. 24, 142.

Ellis, G. R. A. and McCulloch, P. M. 1966, Nature 211, 1070.

Énomé, S. and Tanaka, H. 1971, In "Solar Magnetic Fields" (ed. R. Howard), IAU Symp. 43, D. Reidel, Dordrecht, Holland, p. 413.

Evans, L. G., Fainberg, J., and Stone, R. G. $\quad$ 1971, Solar Phys. 21, 198.

Fainberg, J. and Stone, R. G. 1970a, Solar Phys. 15, 222.

Fainberg, J. and Stone, R. G. 1970b, Solar Phys. 15, 433.

Fainberg, J. and Stone, R. G. $\quad$ 1971, Solar Phys. 17, 392.

Feix, G. $\quad 1972$, Astron. Astrophys. 16, 268.

Flett, A. M., Foster, P. R., Strachan, P., and Thornton, D. C. $\quad$ 1971, Solar Phys. 20, 317.

Fokker, A. D. $\quad 1970$, Solar Phys. 11, 92.

Fokker, A. D. 1971, Solar Phys. 19, 472.

Fokker, A. D. (ed.) 1971, Proceedings of the First Meeting of the Committee of European Solar Astronomers, Utrecht, Holland.

Fomichev, V. V. and Chertok, I. M. 1970, Astron. Zh. 47, $322 \quad 1970$, Soviet Astron.-AJ 14, 261.

Garczynska, I. 1971, Acta Astron. 21, 395.

Gel'freikh, G. B., Zhitnik, I. A., and Livshits, M. A. $\quad$ 1970, Astron. Zh. 47, $329 \quad$ 1970, Soviet Astron.$A J 14,266$.

Gordon, I. M. 1970, Astrophys. Letters 5, 251.

Gorgolewski, S. 1972, Bull. Acad. Pol. Sci., Ser. Sci. Math. Astron. Phys. (in press).

Gotwols, B. L. 1972, Solar Phys. 25, 232.

Graedel, T. E. $\quad 1970$, Astrophys. J. 160, 301.

Graedel, T. E. and Lanzerotti, L. $\quad$ 1971, J. Geophys. Res. 76, 6972.

Grognard, R. J.-M. and McLean, D. J. 1973 , Solar Phys. 29, 149.

Haddock, F. T. and Graedel. T. E. $\quad$ 1970, Astrophys. J. 160, 293.

Hagen, J. P., Swanson, P. N., Haas, R. W., Wefer, F. L., and Vogt, R. W. 1971, Solar Phys. 21, 286.

Hansen, R. T., Garcia, C. J., Grognard, R. J.-M., and Sheridan, K. V. 1971, Proc. Astron. Soc. Australia 2, 57.

Harries, J. R. 1970, Solar Phys. 13, 467,

Hudson, H. S. and Ohki, K. 1972, Solar Phys. 23, 155.

Ishiguro, M. 1971, Proc. Res. Inst. Atmos. Nagoya Univ. 18, 73.

Ishiguro, M., Énomé, S., and Tanaka, H. 1972, Proc. Res. Inst. Atmos. Nagoya Univ. 19, 105.

Kai, K. 1970, Solar Phys. 11, 456. 
Kai, K. 1973, (to be published).

Kaufmann, P., Matsuura, O. T., and Marques Dos Santos, P. $\quad$ 1970, Solar Phys. 14, 190.

Kislyakov, A. G. $\quad 1970$, Usp. Fiz. Nauk. 101, $607 \quad$ 1971, Soviet Phys. Usp. 13, 495.

Krygier, B. 1970, Acta Astron. 20, 149.

Kundu, M. R. $\quad 1970$, Solar Phys. 13, 348.

Kundu, M. R. 1971, Solar Phys. 21, 130.

Kundu, M. R. $\quad$ 1972, Solar Phys. 25, 108.

Kundu, M. R., Erickson, W. C., Jackson, P. D., and Fainberg, J. $\quad$ 1970, Solar Phys, 14, 394.

Kundu, M. R. and McCullough, T. P. 1972, Solar Phys. 24, 133.

Labrum, N. R. and Steward, R. T. $\quad$ 1970, Proc. Astron. Soc. Australia 1, 316.

Lacombe, C. and Mangeney, A. 1969, Astron. Astrophys. 1, 325.

Lacombe, C. and Moller Pederson, B. 1971, Astron. Astrophys. 15, 406.

Lantos-Jarry, M. F. $\quad 1970$, Solar Phys. 15, 40.

McLean, D. J. and Sheridan, K. V. 1972, Solar Phys. 26, 76.

McLean, D. J., Sheridan, K. V., Stewart, R. T., and Wild, J. P. $\quad$ 1971, Nature 234, 140.

Macris, C. J. (ed.) 1971, Physics of the Solar Corona, D. Reidel, Holland.

Markeev, A. K. and Chernov, G. P. 1970, Astron. Zh. 47, 1044 Soviet Astron.-AJ 14, 835.

Martres, M., Pick, M., and Parks, G. J. $\quad$ 1970, Solar Phys. 15, 48.

Martres, M. J., Pick, M., Soru-Escaut, I., and Axisa, F. $\quad$ 1972, Nature, Phys. Sci. 236, 25.

Mayfield, E. B., Higman, J., and Samson, C. $\quad$ 1970, Solar Phys. 13, 372.

Melrose, D. B. $\quad 1970$ a, Australian J. Phys. 23, 871.

Melrose, D. B. $\quad 1970$ b, Australian J. Phys. 23, 885.

Melrose, D. B. and Sy, W. N. $\quad 1972$, Australian J. Phys. 25, 387.

Newkirk, G. Jnr. 1971, In 'Solar Magnetic Fields' (ed. R. Howard), IAU Symp. 43, D. Reidel, Dordrecht, Holland, p. 547.

Papagiannis, M. D. 1971, In Physics of the Solar Corona (ed. C. J. Macris), D. Reidel, Dordrecht, Holland, p. 317.

Pintér, S. 1972, Bull. Astron. Inst. Czechoslovakia 23, 69.

Richards, D. W. and Straka, R. M. 1971, Nature, Phys. Sci. 233, 92.

Riddle, A. C. $\quad$ 1970, Proc. Astron. Soc. Australia 1, 310.

Riddle, A. C. $\quad$ 1972a, Proc. Astron. Soc. Australia 2, 98.

Riddle, A. C. 1972b, Proc. Astron. Soc. Australia 2 (in press).

Riddle, A. C. 1973 (submitted to Solar Phys.).

Rosenberg, H. 1970, Astron. Astrophys. 9, 159.

Rosenberg, H. $\quad$ 1972, Solar Phys. 25, 188.

Sakurai, K. 1971a, Solar Phys. 16, 125.

Sakurai, K. 1971b, Solar Phys. 16, 198.

Sakurai, K. and Stone, R. G. 1971, Solar Phys. 19, 247.

Scalise, E. Jnr., Basu, J., and Marques Dos Santos, P. 1971, Astron. Astrophys. 13, 471.

Schatten, K. H. $\quad 1970$, Solar Phys. 12, 484.

Schmahl, E. J. 1972, Proc. Astron. Soc. Australia 2, 95.

Schmahl, E. J. 1973, (in preparation).

Shimabukuro, F. I. $\quad 1970$ a, Solar Phys. 20, 149.

Shimabukuro, F. I. $\quad 1970$ b, Solar Phys. 15, 424.

Shimabukuro, F. I. $\quad$ 1971, Solar Phys. 18, 247.

Shimabukuro, F. I. $\quad$ 1972, Solar Phys. 23, 169.

Simon, M. 1971, Solar Phys. 21, 297.

Simon, M. and Wickström, B.-A. 1971, Solar Phys. 21, 122.

Slottje, C. $\quad$ 1972, Solar Phys. 25, 210.

Smerd, S. F. $\quad$ 1970, Proc. Astron. Soc. Australia 1, 305.

Smerd, S. F. and Dulk, G. A. 1971, In 'Solar Magnetic Fields' (ed. R. Howard), IAU Symp. 43, D. Reidel, Dordrecht, Holland, p. 116.

Smith, D. F. $\quad 1970 \mathrm{a}$, Adv. Astron. Astrophys. 7, 147.

Smith, D. F. $\quad$ 1970b, Solar Phys. 15, 202.

Smith, D. F. $\quad 1971$, Astrophys. J. 170, 559.

Smith, D. F. $\quad$ 1972a, Astrophys. J. 174, 121.

Smith, D. F. $\quad 1972$ b, Astrophys. J. 174, 643.

Smith, D. F. $\quad 1972$ c, Solar Phys. 23, 191. 
Smith, D. F. 1972d, Astron. Astrophys. 18, 403.

Smith, D. F. and Fung, P. C. W. 1971, J. Plasma Phys. 5, 1.

Smith, D. F. and Sturrock, P. A. 1971, Astrophys. Space Sci. 12, 411.

Sofue, Y., Kawabata, K., Kawajiri, N., and Kawano, N. 1972, Publ. Astron. Soc. Japan $24,309$. Steinberg, J. L. $\quad$ 1972, Astron. Astrophys. 18, 382.

Steinberg, J. L. and Caroubalos, C. 1970, Astron. Astrophys. 9, 329.

Steinberg, J. L., Aubier-Giraud, M., Leblanc, Y., and Boischot, A. 1971 , Astron. Astrophys. $10,362$.

Stewart, R. T. $\quad$ 1972, Proc. Astron. Soc. Australia 2, 100.

Stewart, R. T. 1973 (submitted to Solar Phys.).

Stewart, R. T. and Labrum, N. R. 1972, Solar Phys. 27, 192.

Stone, R. G. and Fainberg, J. 1971, Solar Phys. 20, 106.

Takatura, T. 1971, In 'Solar Magnetic Fields' (ed. R. Howard), IAU Symp. 43, D. Reidel, Dordrecht, Holland, p. 399.

Takakura, T., Ohki, K., Shibuya, N., Fujii, M., Matsuoka, M., Miyamoto, S., Nishimura, J., Oda, M., Ogawera, Y., and Ota, S. 1971, Solar Phys. 16, 454.

Tanaka, H. and Énomé, S. $\quad 1970$, Nature 225, 435.

Tanaka, H. and Énomé, S. 1971, Solar Phys. 17, 408.

Tanaka, H., Énomé, S., Torii, C., Tsukiji, Y., Kobayashi, S., Ishiguro, M., and Arisawa, M. 1970, Proc. Res. Inst. Atmos. Nagoya Univ. 17, 57.

Tarnstrom, G. L. and Phillips, K. W. 1972, Astron. Astrophys. 16, 21.

Teske, R. G., Soyumer, T., and Hudson, H. S. 1971, Astrophys. J. 165, 615.

Wild, J. P. $\quad$ 1970, Proc. Astron. Soc. Australia 1, 365.

Wild, J. P. and Smerd, S. F. $\quad$ 1972, Ann. Rev. Astron. Astrophys. 10, 159.

Zaitsev, V. V., Mityakov, N. A., and Rapoport, V. O. 1972 , Solar Phys. 24, 444.

Zheleznyakov, V. V. $\quad$ 1970, The Radio Emission of the Sun and Planets, Pergamon Press, Oxford, 697 pp.

Zheleznyakov, V. V. and Zaitsev, V. V. $1970 \mathrm{a}$, Astron. Zh. 47, 60 1970a, Soviet Astron.-AJ $14,47$.

Zheleznyakov, V. V. and Zaitsev, V. V. 1970b, Astron. Zh. 47, $308 \quad$ 1970b, Soviet Astron.-AJ 14, 250. 